\title{
EXTRACTIVE DISTILLATION CALCULATIONS BY MODIFIED RELAXATION METHOD*
}

\author{
TAKESHI ISHIKAWA AND MITSUHO HIRATA \\ Department of Industrial Chemistry, Faculty of Engineering, \\ Tokyo Metropolitan University, Tokyo, Japan
}

\begin{abstract}
A modified relaxation procedure is developed for calculations of the multicomponent distillation column. The method is applied to extractive distillation to calculate the product distribution and the composition and temperature profile in the column when feed conditions, flow rates, number of plates, locations of feed plates, and reflux ratio are specified.

The method is simple and numerically stable. Some problems are discussed to demonstrate the feasibility of the procedure.
\end{abstract}

\section{Introduction}

Extractive distillation is an important process for the separation and purification of chemicals produced synthetically and in the separations of other closely boiling components, and especially of azeotropic mixtures, which cannot be separated by ordinary distillation procedure.

Broadly, extractive distillation is distillation in which the volatilities of the key components are altered by addition of a third component, the so-called solvent. Therefore, the system is composed of at least more than three components. Such a system deviates markedly from an ideal mixture.

Several methods have been proposed for solving nonideal multicomponent distillation problems and extractive distillation problems. These methods may be classified into following three categories:

(1) Graphical solutions, namely, the Benedict $\operatorname{method}^{3)}$, Bonilla $\operatorname{method}^{4)}$, Atkins $\operatorname{method}^{2)}$, Lee method $^{8)}$ and Tanaka method ${ }^{16)}$.

(2) Plate-to-plate calculation procedures, namely, The Lewis-Matheson method $^{9)}$ and the Thiele-Geddes $\operatorname{method}^{17)}$, with a $\theta$ method developed by Lyster ${ }^{10}$.

Hirose $^{6}$ ) presented a calculational procedure for solving non-ideal multicomponent distillation problems by combining the Lewis-Matheson method with the modified $\theta$ method.

In recent years, Sadamoto ${ }^{13)}$ developed a method for the calculation of number of plates in an extractive distillation column by using the modified $\theta$ method.

Finally, (3) there is the analytical method proposed by Sugie et al. ${ }^{15)}$. This procedure applies the analytical method developed by Acrivos ${ }^{1}$ to extractive distillation calculations.

* Received on August 25, 1971

Presented at the 4th Autumn Meeting of the Soc. of Chem. Engrs., Japan, Oct. 1970
Graphical methods of type (1) are intuitive and lend themselves to an easy understanding of the idea of distillation calculations, but the procedures are rather complicated and time-consuming. Moreover, in these methods the calculations are carried out under the special assumption that solvent concentration in the enriching section of the column is constant and determination of the locations of the feed plates is approximate, hence the results obtained by these methods are not always rigorous.

On the other hand, the plate-to-plate calculation methods of type (2) are excellent. However, in these methods the values of the liquid compositions in the enriching section of the extractive distillation column are occasionally negative, because the initial values of the terminal compositions are not adequate. Therefore these methods often lead to no solution, unless a great deal of experience and judgement are applied in choosing initial values. Also, the results in each iteration obtained from plate-to-plate calculation methods have no physical meanings, and only the convergence values are useful.

Finally, the analytical method of type (3) is also an interesting procedure. The method, however, is complicated in comparison with others and involves the special assumption that solvent concentration in the enriching section of the column is constant. Furthermore, it is questionable whether this analytical method can be applied to systems deviating largely from an ideal mixture.

In this paper, a new method is developed for calculation of the multicomponent distillation column. The method was applied to extractive distillation for calculating the product distribution and the composition and temperature profile in the column when feed conditions, flow rates, number of plates, locations of feed plates, and reflux ratio are specified.

This method employs the modified relaxation algo- 


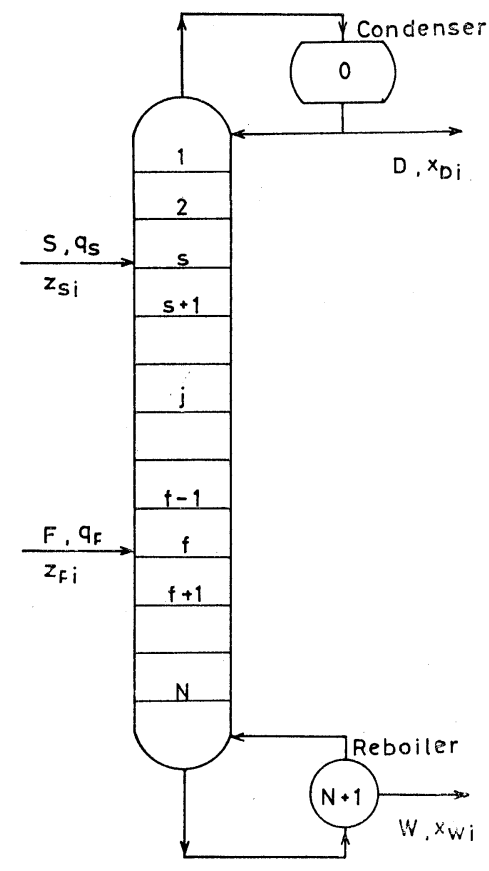

Fig. 1 A model for the extractive distillation column

rithm for the solution of non-linear simultaneous equations. Therefore, the method cannot be classified into any one of the three categories described above. We consider that it belongs to a fourth type.

This procedure, as described later, makes use of unsteady state equations for the determination of the steady state solution. Therefore, this method is equivalent to having a pilot plant column and actually operating it to obtain the answers. Also, problems in the sellection of initial values are simple, and no special consideration for the least amount of components involved in distillate and/or bottoms is necessary.

\section{Mathematical Model}

The extractive distillation column shown in Fig. 1 is considered as an ideal model. This column has $N$ equilibrium plates, including a solvent feed plate and a feed plate, and has a condenser at the top and a reboiler at the bottom. For the convenience of calculations the stages are numbered from top to bottom, with the condenser as zeroth stage and reboiler as the $N+1$ th stage.

Fig. 2 shows such an ideal equilibrium stage, excluding condenser, solvent feed plate, feed plate and reboiler.

For the time period or interval from $t$ to $t+\Delta t$, the component-material balance on the $j$ th stage as shown in Fig. 2 is given by the integral-difference equation with the law of conservation of mass.

$$
\begin{aligned}
& \int_{t}^{t+\Delta t}\left[\left(V_{j+1} y_{i, j+1}+L_{j-1} x_{i, j-1}\right)-\left(V_{j} y_{i j}+L_{j} x_{i j}\right)\right] d t \\
& \quad=\left[H_{j}^{L} x_{i j}\right]_{t+\Delta t}-\left[H_{j}^{L} x_{i j}\right]_{t}
\end{aligned}
$$

where $j$ refers to the stage number and $i$ refers to the component number.

$H_{j}^{L}$ refers to the total moles of liquid holdup on the

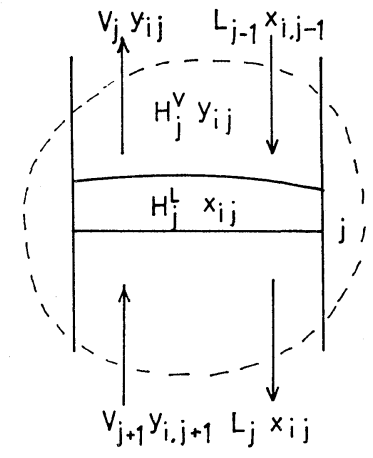

Fig. 2 An ideal equilibrium stage in the column

$j$ th stage and $V$ and $L$ refer to the vapor and liquid flow rates, respectively.

The vapor holdup, $H_{j}^{v}$, in Fig. 2 is neglected in the material balance because it is usually small relative to the liquid holdup.

By use of the mean value theorem of integral and the mean value theorem of differential calculus, the left-hand and right-hand sides, respectively, of Eq.(1) may be stated in the following form.

$$
\begin{gathered}
\int_{t}^{t+\Delta t}\left[\left(V_{j+1} y_{i, j+1}+L_{j-1} x_{i, j-1}\right)-\left(V_{j} y_{i j}+L_{j} x_{i j}\right)\right] d t \\
=\left[\left(V_{j+1} y_{i, j+1}+L_{j-1} x_{i, j-1}\right)-\left(V_{j} y_{i j}+L_{j} x_{i j}\right)\right]_{a v} \Delta t \\
\quad\left[H_{j}^{L} x_{i j}\right]_{t+\Delta t}-\left[H_{j}^{L} x_{i j}\right]_{t}=\Delta t\left[\frac{d\left(H_{j}^{L} x_{i j}\right)}{d t}\right]_{t+\varepsilon \Delta t}
\end{gathered}
$$

Substituting Eqs.(2) and (3) into Eq.(1) yields

$$
\begin{gathered}
{\left[\frac{d\left(H_{j}^{L} x_{i j}\right)}{d t}\right]_{t+\varepsilon \Delta t}=\left[\left(V_{j+1} y_{i, j+1}+L_{j-1} x_{i, j-1}\right)\right.} \\
\left.-\left(V_{j} y_{i j}+L_{j} x_{i j}\right)\right]_{a v}
\end{gathered}
$$

It is assumed that the liquid holdup on each stage remains constant with respect to time, that is,

$$
\frac{d H_{j}^{L}}{d t}=0
$$

Furthermore, by taking the limit of each term of Eq.(4) as $\Delta t$ approaches zero, following differential equation is obtained.

$$
\begin{gathered}
H_{j}^{L}\left(\frac{d x_{i j}}{d t}\right)_{t}=\left[\left(V_{j+1} y_{i, j+1}+L_{j-1} x_{i, j-1}\right)\right. \\
\left.-\left(V_{j} y_{i j}+L_{j} x_{i j}\right)\right]_{t}
\end{gathered}
$$

If all the compositions and the flow rates at time $t$ are known, it is then possible to calculate all the concentration gradients, $d x_{i j} / d t$.

However, an implicit form of the finite difference approximation for the differential equation is

$$
\left(\frac{d x_{i j}}{d t}\right)_{t}=\frac{\left(x_{i j}\right)_{t+\Delta t}-\left(x_{i_{j}}\right)_{t}}{\Delta t}
$$

For the convenience of calculation, consider time $t$ to be iteration $n$ and $t+\Delta t$ to be iteration $n+1$. Then a combination of Eqs.(6) and (7) leads to

$$
\begin{aligned}
& x_{i j}^{n+1}=x_{i j}^{n}+\mu_{j}\left[\left(V_{j+1} y_{i, j+1}+L_{j-1} x_{i, j-1}\right)\right. \\
& \left.\quad-\left(V_{j} y_{i j}+L_{j} x_{i j}\right)\right]^{n}
\end{aligned}
$$

where $\mu_{j}$ is equal to $\left(\Delta t / H_{j}^{L}\right)$ and the relaxation factor. Eq.(8) is also the working equation of the 
procedure proposed by $\operatorname{Rose}^{13)}$. For the condenser, the solvent feed plate, the feed plate and the reboiler, respectively, similar but slightly different equations can be written as follows,

$$
\begin{aligned}
x_{i 0}^{n+1}= & x_{i 0}^{n}+\mu_{0}\left[V_{1} y_{i 0}-L_{0} y_{i 0}-D x_{D i}\right]^{n} \\
x_{i s}^{n+1}= & x_{i s}^{n}+\mu_{s}\left[\left(S z_{S i}+V_{s+1} y_{i, s+1}+L_{s-1} x_{i, s-1}\right)\right. \\
& \left.\quad-\left(V_{s} y_{i s}+L_{s} x_{i s}\right)\right]^{n} \\
x_{i f}^{n+1}= & x_{i f}^{n}+\mu_{f}\left[\left(F z_{F i}+V_{f+1} y_{i, f+1}+L_{f-1} x_{i, f-1}\right)\right. \\
& \left.-\left(V_{f} y_{i f}+L_{f} x_{i f}\right)\right]^{n} \\
x_{i, N+1}^{n+1}= & x_{i, N+1}^{n}+\mu_{N+1}\left[L_{N} x_{i N}-V_{N+1} y_{i, N+1}\right. \\
& \left.\quad-W x_{W i}\right]^{n}
\end{aligned}
$$

If the compositions and flow rates at any iteration (n) are known, Eqs. (8) (12) may be used to calculate the compositions at iteration $(n+1)$, and the process repeated to obtain values for iteration $(n+2)$, and so on. In this calculation, the values of vapor compositions, $y_{i j}$, are obtained from the corresponding values of liquid compositions, $x_{i j}$, by use of the vapor-liquid equilibrium relation.

\section{Method of Computations}

Assuming constant molal overflow and that the liquid holdup is equal for all stages of the column, the vapor and liquid flow rates in each section of the column are the following,

for the solvent recovery section,

$$
\begin{aligned}
& L=R D \\
& V=(R+1) D
\end{aligned}
$$

for the enriching section,

$$
\begin{aligned}
& L^{\prime \prime}=R D+S q_{S} \\
& V^{\prime \prime}=(R+1) D+S\left(1-q_{S}\right)
\end{aligned}
$$

for the recovery section,

$$
\begin{aligned}
& L^{\prime}=R D+S q_{S}+F q_{F} \\
& V^{\prime}=(R+1) D-S\left(1-q_{S}\right)-F\left(1-q_{F}\right)
\end{aligned}
$$

where $R$ is reflux ratio.

When the thermal conditions, the compositions and flow rates of feeds, the amounts of the distillate stream, number of plates, locations of feed plates, and reflux ratio are specified, calculations may be started using feed composition as the initial values of the liquid compositions for all stages of the column. The first step is the use of the basic equation for the condenser to calculate the compositions of the liquid on this stage at the first iteration. The second step is to use the basic equation to calculate the compositions of the first stage at the first iteration.

In the same manner the compositions at first iteration are calculated for each of the other stages from top to bottom. Alternatively the calculations can begin at the bottom and proceed upward.

In this method, as the calculation for each stage is independent of that for all other stages, the above calculations can start from any arbitrary stage and to proceed upward or downward.

Now consider calculation from top to bottom. In Rose's method, when the compositions of the $j$ th stage at $n$th iterations, $x_{i, j-1}^{n}$, had been used as the compositions of the above stage. Therefore, the method may be called mathematically a simultaneous point relaxation method.

This method is stable, but the convergence rate is generally too slow for practical use, and if feed compositions are used as the initial values of the liquid compositions for all stages of the column, further calculation cannot proceed because the correction term of the right-hand side in Eqs. (8) (12) becomes zero.

Accordingly, to increase the rate of convergence and to be able to apply for distillation calculations of the non-ideal multicomponents, we propose the following procedures.

Instead of $x_{i, j-1}^{n}$ in Eq.(8), the values of the liquid compositions of the above stage calculated at $(n+1)$ th iteration, that is, $x_{i, j-1}^{n+1}$, were used as the compositions of the $j-1$ th stage. Consequently, Eq.(8) may be written as follows.

$$
\begin{gathered}
x_{i j}^{n+1}=x_{i j}^{n}+\mu_{j}\left[\left(V_{j+1} y_{i, j+1}^{n}+L_{j-1} x_{i, j-1}^{n+1}\right)\right. \\
\left.-\left(V_{j} y_{i j}^{n}+L_{j} x_{i j}^{n}\right)\right]
\end{gathered}
$$

This is the basic equation for our method. Relative to Rose's method this may be called a successive point relaxation method. It is as stable as Rose's method, but the rate of convergence is more rapid. For the condenser, the feed plates and the reboiler, an equation of this same kind can be written.

Alternatively, when the calculations are begun at the bottom of the column and proceed upward, by means of a manner similar to that described above, but slightly different, the basic equations were easily derived. Briefly, instead of $y_{i, j+1}^{n}$ in Eq.(8), $y_{i, j+1}^{n+1}$ are used as the vapor compositions of the $j+1$ th stage. Therefore, Eq.(8) may be written as

$$
\begin{gathered}
x_{i j}^{n+1}=x_{i j}^{n}+\mu_{j}\left[\left(V_{j+1} y_{i, j+1}^{n+1}+L_{j-1} x_{i, j-1}^{n}\right)\right. \\
\left.-\left(V_{j} y_{i j}^{n}+L_{j} x_{i j}^{n}\right)\right]
\end{gathered}
$$

In this case, it is emphasized that the vapor compositions, $y_{i, j+1}^{n+1}$, in equilibrium with the liquid, $x_{i, j+1}^{n+1}$, on the $j+1$ th stage at $(n+1)$ th iteration must be evaluated before Eq.(20) is applied to the $j$ th stage. Thus, for simplicity, calculation from top to bottom of the column may be recommended.

For the calculation of the vapor compositions to be in equilibrium with the liquid, relation for the nonideal multicomponent vapor-liquid equilibrium has to be used, because in extractive distillation a solvent is added to increase the nonideality of the system. The calculations of such a system may be carried out by the following procedure.

In this system, the vapor-liquid equilibrium ratio depends on the temperature, the pressure and the compositions. Hence when the liquid compositions are given, by use of the applicable activity coefficientliquid composition relation, for example, the Wilson equation $^{18)}$ or the Margules equation ${ }^{11)}$, the activity coefficients were computed.

Then assuming a temperature and proceeding until $\left(\sum y_{i j}-1\right)$ is less than a specified tolerance, the temperature was corrected by the Newton-Raphson iteration method. For the purpose of decreasing the number of iterations in this calculation, the following device 


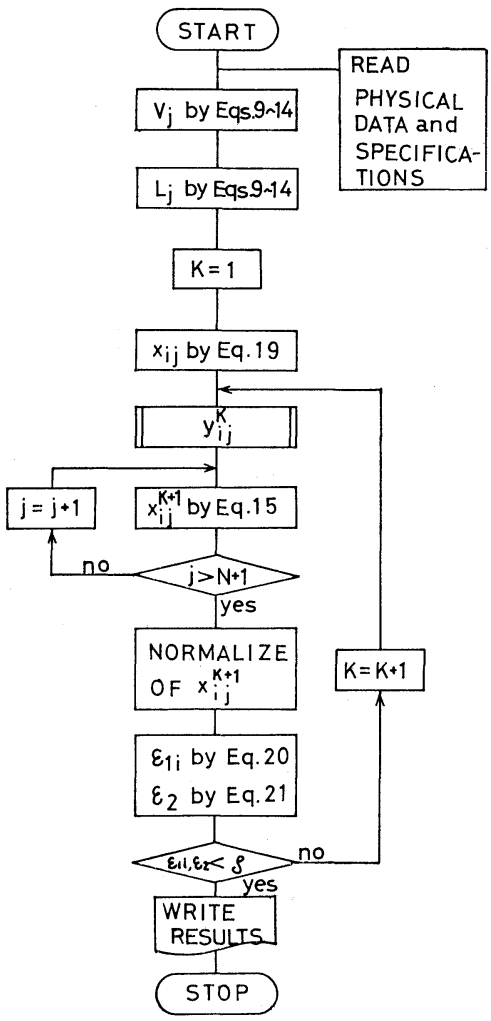

Fig. 3 Flow diagram for the computer calculations

is used. The initial values of the temperature for the first stage calculated, for example at top or bottom of the column, is taken equal to the temperature defined by the relation

$$
T_{j}^{0}=\sum_{i=1}^{N C} x_{j}^{0} T_{b i}
$$

where $T_{b i}$ is a boiling point for the pure components consisting of the system at the pressure and $x_{i}^{0}$ is the initial values of the liquid compositions. If the converged value of the temperature was determined by means of the procedure interpreted before, that value is used as the initial value of the stage below and same procedure is continued.

\section{Computational Procedure}

Computational procedure may be written as follows. Step 1. Relaxation factor, $\mu_{j}$, is given as the reciprocal number of two to five times the summation of amounts of solvent feed and feed per unit time, from a large number of trials to avoid divergence and instability in calculations, that is,

$$
\mu_{j}=\frac{1}{(2 \sim 5) \times(S+F)}
$$

Step 2. Calculate the vapor and liquid flow rates of each section by use of Eqs. (13) to (18).

Step 3. Assume an initial composition on each stage. It is convenient to use overall feed composition presented by the following equation as the initial values,

$$
x_{i j}^{0}=\frac{S z_{S i}+F z_{F i}}{S+F}
$$

Table 1 Specifications of Example 1

\begin{tabular}{lrlllll}
\hline$F$ & 100.0 & $N T 10$ & \multicolumn{3}{c}{$V-L$ relation } \\
$D$ & 40.0 & $N F \quad 4$ & Comp. & $\alpha_{i 3}$ & $z_{F i}$ \\
$W$ & 60.0 & Total & 1 & 3.0 & 0.3 \\
$q$ & 1.0 & condenser & 2 & 2.0 & 0.4 \\
$R$ & 3.0 & & & 3 & 1.0 & 0.3 \\
\hline
\end{tabular}

$N T:$ number of total plates

$N F:$ feed plate numbered from top

Comp.: component

$\alpha$ : relative volatility

Step 4. Evaluate vapor composition $y_{i j}^{n}$, that is in equilibrium with the liquid, $x_{i j}^{n}$.

Step 5. Solve the basic equations, Eq.(19), for $x_{i j}^{n+1}$ 's, using the successive relaxation method.

Step 6. If the values of the liquid compositions determined in Step (5) are negative because of over-correction, to decrease the values of the relaxation factor the applicable constant is multiplied by it and then the calculation proceeds, using the new value in Step (5).

On the other hand, if the value is not negative, go on to the succeeding step.

Step 7. Normalize the liquid compositions determined in Step (5).

Step 8. Repeat Step (4) through Step (7) unitil the following equations are satisfied.

$$
\frac{\left|F z_{F i}+S z_{S i}-D x_{D i}^{n}-W x_{W i}^{n}\right|}{F z_{F i}+S z_{S i}} \leqq \varepsilon_{1 i}
$$

where $\varepsilon_{1 i}$ and $\varepsilon_{2}$ are tolerances. Fig. 3 shows the flow diagram for computer calculations of such a procedure. In Fig.3, the repetitions for the component and the stage were omitted, to avoid complexity on the diagram. Also, the flow diagram for calculation of the vapor compositions was omitted because of space limitations.

\section{Illustrative Examples}

This method has been programed for a FACOM 270-30 digital computer at Computer Center of Tokyo Metropolitan University, and many test problems have been successfully solved without relying on special experience.

The computer running time for the method is proportional to the number of components and the number of stages in the column. For the problems tested, the computing time was about 0.04 seconds per component per stage per iteration.

\section{Example 1}

In confirmation of availability of the new method, firstly, the same problem as was described in our previous paper ${ }^{14)}$ was attempted.

The specifications of the problem are shown in Table 1. Briefly, consider the distillation of an ideal system consisting of three components. The column has 12 stages, including a total condenser and a reboiler. 
Table 2 Results of Example 1

\begin{tabular}{|c|c|c|c|c|c|c|c|c|c|}
\hline \multirow[t]{2}{*}{ Stage No. } & \multirow[t]{2}{*}{$j$} & \multicolumn{3}{|c|}{ Composition profile $x$} & \multirow[t]{2}{*}{ Sum $x$} & \multicolumn{3}{|c|}{ Composition profile $x$} & \multirow[t]{2}{*}{ Sum $x$} \\
\hline & & & & 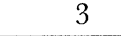 & & & & . & \\
\hline & & \multicolumn{4}{|c|}{ 5th Iteration } & \multicolumn{4}{|c|}{ 30th Iteration } \\
\hline \multirow[t]{4}{*}{ Distillate } & 0 & 0.63572 & 0.31814 & 0.04614 & 1.00000 & 0.66119 & 0.32488 & 0.01393 & 1.00000 \\
\hline & 1 & 0.50803 & 0.38136 & 0.11062 & 1.00001 & 0.55548 & 0.40941 & 0.03511 & 1.00000 \\
\hline & 2 & 0.43034 & 0.40698 & 0.16268 & 1.00000 & 0.46414 & 0.46490 & 0.07096 & 1.00000 \\
\hline & 3 & 0.37729 & 0.41437 & 0.20834 & 1.00000 & 0.38661 & 0.48600 & 0.12739 & 1.00000 \\
\hline \multirow[t]{7}{*}{ Feed } & 4 & 0.33940 & 0.40840 & 0.25221 & 1.00001 & 0.32056 & 0.47117 & 0.20826 & 0.99999 \\
\hline & 5 & 0.33678 & 0.40883 & 0.25439 & 1.00000 & 0.29002 & 0.49825 & 0.21173 & 1.00000 \\
\hline & 6 & 0.33430 & 0.40916 & 0.25653 & 0.99999 & 0.25597 & 0.52671 & 0.21732 & 1.00000 \\
\hline & 7 & 0.30002 & 0.43600 & 0.26398 & 1.00000 & 0.21901 & 0.55352 & 0.22747 & 1.00000 \\
\hline & 8 & 0.24841 & 0.47052 & 0.28107 & 1.00000 & 0.17978 & 0.57274 & 0.24748 & 1.00000 \\
\hline & 9 & 0.18694 & 0.49384 & 0.32022 & 1.00000 & 0.13897 & 0.57327 & 0.28776 & 1.00000 \\
\hline & 10 & 0.12283 & 0.47691 & 0.40026 & 1.00000 & 0.09768 & 0.53740 & 0.36492 & 1.00000 \\
\hline \multirow[t]{2}{*}{ Bottoms } & 11 & 0.06877 & 0.39676 & 0.53446 & 0.99999 & 0.05857 & 0.44662 & 0.49481 & 1.00000 \\
\hline & & \multicolumn{4}{|c|}{ 10th Iteration } & \multicolumn{4}{|c|}{ 42nd Iteration (Final results) } \\
\hline \multirow[t]{4}{*}{ Distillate } & 0 & 0.68720 & 0.28868 & 0.02412 & 1.00000 & 0.66105 & 0.32525 & 0.01370 & 1.00000 \\
\hline & 1 & 0.57623 & 0.36310 & 0.06067 & 1.00000 & 0.55551 & 0.40997 & 0.03452 & 1.00000 \\
\hline & 2 & 0.48362 & 0.41236 & 0.10402 & 1.00000 & 0.46443 & 0.46542 & 0.07014 & 0.99999 \\
\hline & 3 & 0.40077 & 0.44098 & 0.15825 & 1.00000 & 0.38701 & 0.48641 & 0.12658 & 1.00000 \\
\hline \multirow[t]{7}{*}{ Feed } & 4 & 0.32786 & 0.44586 & 0.22629 & 1.00001 & 0.32091 & 0.47135 & 0.20775 & 1.00001 \\
\hline & 5 & 0.29284 & 0.47571 & 0.23145 & 1.00000 & 0.29047 & 0.49842 & 0.21111 & 1.00000 \\
\hline & 6 & 0.25217 & 0.50846 & 0.23937 & 1.00000 & 0.25652 & 0.52696 & 0.21653 & 1.00001 \\
\hline & 7 & 0.20873 & 0.53837 & 0.25289 & 0.99999 & 0.21962 & 0.55398 & 0.22640 & 1.00000 \\
\hline & 8 & 0.16499 & 0.55699 & 0.27801 & 0.99999 & 0.18044 & 0.57361 & 0.24595 & 1.00000 \\
\hline & 9 & 0.12270 & 0.55171 & 0.32560 & 1.00001 & 0.13964 & 0.57480 & 0.28556 & 1.00000 \\
\hline & 10 & 0.08344 & 0.50586 & 0.41070 & 1.00000 & 0.09832 & 0.53975 & 0.36193 & 1.00000 \\
\hline \multirow[t]{2}{*}{ Bottoms } & 11 & 0.04852 & 0.40766 & 0.54382 & 1.00000 & 0.05907 & 0.44957 & 0.49136 & 1.00000 \\
\hline & & \multicolumn{4}{|c|}{ 20th Iteration } & \multicolumn{4}{|c|}{ Results of Shono } \\
\hline \multirow[t]{4}{*}{ Distillate } & 0 & 0.66445 & 0.32031 & 0.01524 & 1.00000 & 0.6613 & 0.3250 & 0.0137 & 1.0000 \\
\hline & 1 & 0.55806 & 0.40353 & 0.03841 & 1.00000 & 0.5558 & 0.4098 & 0.0344 & 1.0000 \\
\hline & 2 & 0.46468 & 0.45982 & 0.07550 & 1.00000 & 0.4647 & 0.4653 & 0.0700 & 1.0000 \\
\hline & 3 & 0.38604 & 0.48210 & 0.13186 & 1.00000 & 0.3872 & 0.4863 & 0.1265 & 1.0000 \\
\hline \multirow[t]{7}{*}{ Feed } & 4 & 0.31997 & 0.46902 & 0.21100 & 0.99999 & 0.3210 & 0.4713 & 0.2077 & 1.0000 \\
\hline & 5 & 0.28918 & 0.49592 & 0.21490 & 1.00000 & 0.2906 & 0.4983 & 0.2110 & 1.0000 \\
\hline & 6 & 0.25487 & 0.52398 & 0.22115 & 1.00000 & 0.2567 & 0.5269 & 0.2164 & 1.0000 \\
\hline & 7 & 0.21761 & 0.55002 & 0.23237 & 1.00000 & 0.2198 & 0.5539 & 0.2263 & 1.0000 \\
\hline & 8 & 0.17805 & 0.56785 & 0.25410 & 1.00000 & 0.1806 & 0.5736 & 0.2457 & 1.0000 \\
\hline & 9 & 0.13697 & 0.56612 & 0.29691 & 1.00000 & 0.1398 & 0.5749 & 0.2852 & 1.0000 \\
\hline & 10 & 0.09563 & 0.52736 & 0.37701 & 1.00000 & 0.0985 & 0.5400 & 0.3615 & 1.0000 \\
\hline Bottoms & 11 & 0.05686 & 0.43458 & 0.50867 & 1.00001 & 0.0592 & 0.4500 & 0.4907 & 1.0000 \\
\hline
\end{tabular}

Fig. 4 Liquid composition profile for Example 1

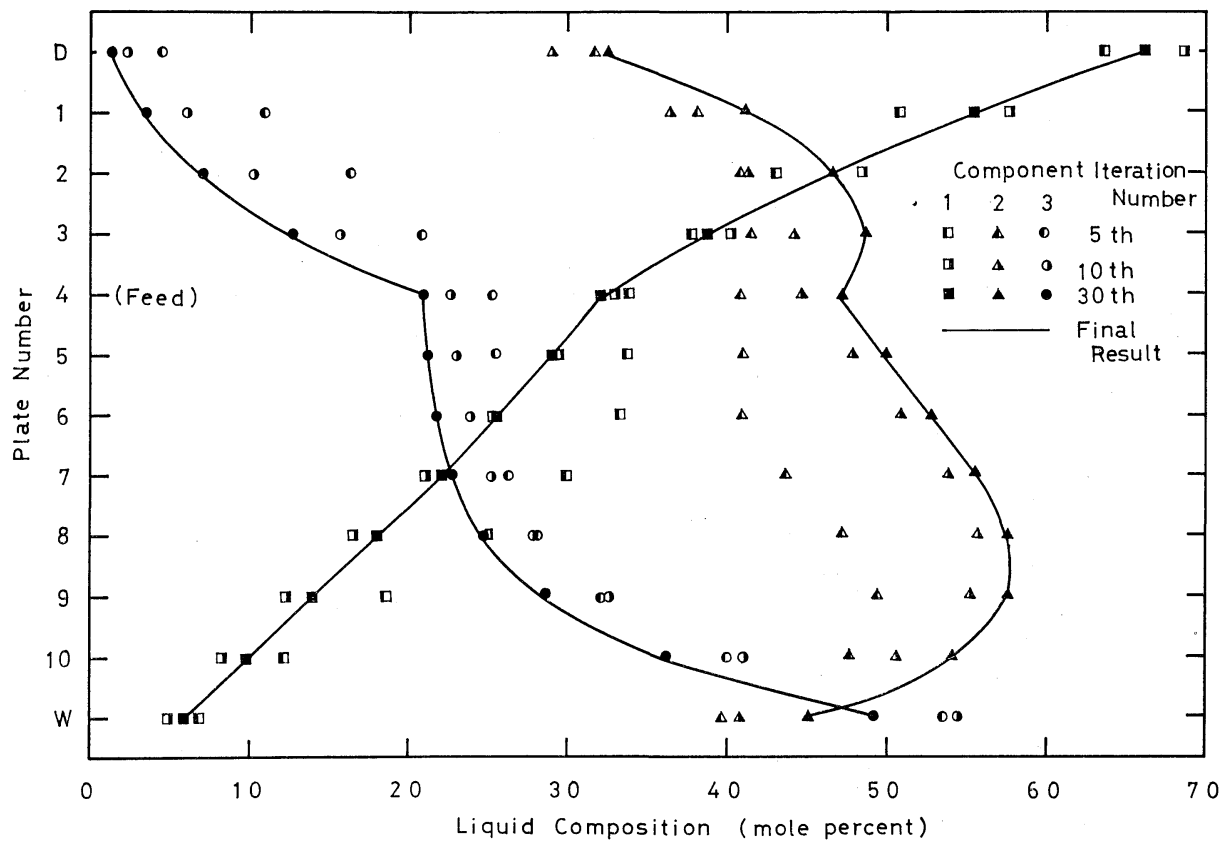


Starting with feed composition used as initial values of the liquid compositions for all stages of the column, a solution was obtained in 42 iterations. Table 2 and Fig.4 give the computational results of this problem. In Table 2 liquid composition profiles $x_{i j}$, computed at the end of the 5th, 10th, 20th, 30th, and last iterations. It is observed that $x_{i j}$ changed only slightly after the 30th iteration.

\begin{tabular}{|c|c|c|c|c|}
\hline $\begin{array}{l}\text { Iteration } \\
\text { number }\end{array}$ & $\varepsilon_{11}$ & $\varepsilon_{12}$ & rrors $\varepsilon_{13}$ & $\varepsilon_{2}$ \\
\hline 5 & $3.89 \times 10^{-2}$ & $7.23 \times 10^{-2}$ & $1.42 \times 10^{-1}$ & $1.57 \times 10^{-2}$ \\
\hline 10 & $3.91 \times 10^{-3}$ & $9.55 \times 10^{-2}$ & $1.23 \times 10^{-1}$ & $2.20 \times 10^{-3}$ \\
\hline 20 & $1.34 \times 10^{-3}$ & $2.94 \times 10^{-2}$ & $3.78 \times 10^{-2}$ & $8.93 \times 10^{-5}$ \\
\hline 30 & $1.14 \times 10^{-3}$ & $5.34 \times 10^{-3}$ & $8.26 \times 10^{-3}$ & $3.68 \times 10^{-6}$ \\
\hline 40 & $6.13 \times 10^{-4}$ & $7.56 \times 10^{-4}$ & $1.62 \times 10^{-3}$ & $1.36 \times 10^{-7}$ \\
\hline 42 & $4.65 \times 10^{-4}$ & $3.91 \times 10^{-4}$ & $9.87 \times 10^{-4}$ & $5.18 \times 10^{-8}$ \\
\hline \multicolumn{5}{|c|}{$\begin{array}{l}\varepsilon_{1 i}=\frac{\left|f_{i}-\left(d_{i}\right)_{c a}-\left(w_{i}\right)_{c a}\right|}{f_{i}} \\
\varepsilon_{2}=\sum_{i=1}^{N C} \sum_{j=1}^{N+1}\left(\frac{x_{i j}^{n+1}-x_{i j}^{n}}{x_{i j}^{n}}\right)^{2}\end{array}$} \\
\hline
\end{tabular}

Table 4 Specifications and physical data of Example 2

\begin{tabular}{lllll}
$F=1.0$ & $q_{F}=1.0$ & $N T=15$ & \multicolumn{2}{c}{ Feeds compositions } \\
$S=2.0$ & $q_{S}=1.0$ & $N S=3$ & $z_{F 1}=0.9$ & $z_{S 1}=0.0$ \\
$D=0.5$ & $R=3.0$ & $N F=10$ & $z_{F 2}=0.1$ & $z_{S 2}=0.0$ \\
$W=2.5$ & $\mu=0.1$ & & $z_{F 3}=0.0$ & $z_{S 3}=1.0$
\end{tabular}

\begin{tabular}{|c|c|c|c|c|c|}
\hline \multicolumn{6}{|c|}{ Margules parameters and Antoine's constants used } \\
\hline $\begin{array}{c}\text { Comp. } \\
\text { No. }\end{array}$ & & $\begin{array}{l}\text { Antoine's } \\
\text { constant }{ }^{17}\end{array}$ & & $\begin{array}{l}\text { Marg } \\
\text { paran }\end{array}$ & $\begin{array}{l}\text { les } \\
\text { eters }^{17)}\end{array}$ \\
\hline 2.0. & $\begin{array}{c}A_{i} \\
7.23967\end{array}$ & $\begin{array}{c}B_{i} \\
1279.8701\end{array}$ & $\begin{array}{c}C_{i} \\
237.5\end{array}$ & $\begin{array}{l}A_{12}= \\
0.2885\end{array}$ & $\begin{array}{l}A_{21}= \\
0.2501\end{array}$ \\
\hline 2 & 7.24299 & 1397.9290 & 238.9 & $\begin{array}{c}A_{13}= \\
0.3197\end{array}$ & $\begin{array}{l}A_{31}= \\
0.0828\end{array}$ \\
\hline 3 & 7.96681 & 1688.2099 & 228.0 & $\begin{array}{c}A_{23}= \\
0.0019 \\
A_{123}= \\
0.2454\end{array}$ & $\begin{array}{l}A_{32}= \\
0.0242\end{array}$ \\
\hline
\end{tabular}

The results obtained by Shono ${ }^{14)}$ are also shown in the last columns of Table 2.

It can be seen from this table that the results of this work agree very well with those of Shono. Consequently, it is confirmed that this new method is useful.

Table 3 shows the variation for the errors of each component in this problem. There are convergence differences depending on the component. As shown in Fig.4, however, the results obtained at the end of the 30th iteration could be considered sufficiently accurate in practical use.

In this problem, when $\varepsilon_{1 j}=10^{-3}$ and $\varepsilon_{2}=10^{-6}$, the computing running time, including the printout of input data and detailed results of the final iteration, was about 30 seconds. When the same problem was solved by Rose's method, 349 iterations were required for a converged solution and the computing time was about 300 seconds.

\section{Example 2}

Now consider separation of acetone from acetone(1) -acetonitrile(2) mixture by extractive distillation using water(3) as solvent. The problem specifications and physical data are given in Table 4.

Briefly, the column has 15 equilibrium plates with a total condenser and a reboiler. The solvent enters at the 3rd plate, and the feed enters at the 10th plate. The column is operated at atmospheric pressure.

Starting with feed composition used as the initial values of the liquid compositions for all stages of the column, and assuming relaxation factor is 0.1 , a solution was obtained in 42 iterations. Table 5 gives the computational results of this problem.

\section{Conclusions}

A new method for calculation of the multicomponent distillation column has been developed. The calculation solves all unsteady-state equations simultaneously by a modified relaxation method. The method was

Table 5 Final results of Example 2

\begin{tabular}{|c|c|c|c|c|c|c|c|c|}
\hline Stage & $\underset{j}{\text { No. }}$ & $\begin{array}{l}\text { Temp. } \\
{\left[{ }^{\circ} \mathrm{C}\right]}\end{array}$ & 1 & $\begin{array}{c}\text { Composition profile } \\
2\end{array}$ & $x_{i j}$ & 1 & $\begin{array}{c}\text { Composition profile } \\
2\end{array}$ & $y_{i j}$ \\
\hline \multirow[t]{3}{*}{$(D)$} & 0 & & 0.96723 & 0.00014 & 0.03273 & & & \\
\hline & 1 & 60.10 & 0.84949 & 0.00019 & 0.15032 & 0.96723 & 0.00014 & 0.03283 \\
\hline & 2 & 67.65 & 0.59301 & 0.00021 & 0.40678 & 0.87902 & 0.00017 & 0.12081 \\
\hline \multirow[t]{7}{*}{$(S)$} & 3 & 79.45 & 0.25436 & 0.00020 & 0.74544 & 0.68681 & 0.00018 & 0.31302 \\
\hline & 4 & 79.42 & 0.25489 & 0.00041 & 0.74470 & 0.68720 & 0.00037 & 0.31243 \\
\hline & 5 & 79.36 & 0.25613 & 0.00085 & 0.74302 & 0.68815 & 0.00075 & 0.31111 \\
\hline & 6 & 79.22 & 0.25898 & 0.00170 & 0.73932 & 0.69035 & 0.00150 & 0.30816 \\
\hline & 7 & 78.90 & 0.26552 & 0.00343 & 0.73105 & 0.69537 & 0.00299 & 0.30168 \\
\hline & 8 & 78.19 & 0.28091 & 0.00700 & 0.71209 & 0.70687 & 0.00601 & 0.28734 \\
\hline & 9 & 76.44 & 0.32086 & 0.01484 & 0.66430 & 0.73375 & 0.01227 & 0.25397 \\
\hline \multirow[t]{6}{*}{$(F)$} & 10 & 71.58 & 0.44945 & 0.03380 & 0.51675 & 0.80369 & 0.02598 & 0.17034 \\
\hline & 11 & 71.58 & 0.44918 & 0.03389 & 0.51693 & 0.80334 & 0.02605 & 0.17037 \\
\hline & 12 & 71.62 & 0.44798 & 0.03416 & 0.51786 & 0.80283 & 0.02627 & 0.17090 \\
\hline & 13 & 71.77 & 0.44308 & 0.03488 & 0.52204 & 0.80013 & 0.02687 & 0.17302 \\
\hline & 14 & 72.43 & 0.42296 & 0.03669 & 0.54035 & 0.78918 & 0.02848 & 0.18252 \\
\hline & 15 & 75.07 & 0.34736 & 0.04025 & 0.61239 & 0.74383 & 0.03256 & 0.22362 \\
\hline$(W)$ & 16 & 83.84 & 0.16624 & 0.03999 & 0.79377 & 0.57373 & 0.04057 & 0.38571 \\
\hline
\end{tabular}


applied to the calculation of extractive distillation problems.

This method has the following advantage;

(1) Computational procedure is simple and does not require a very large and fast computer.

(2) Each trial gives the exact answer for distillation under the chosen conditions. Accordingly, using this method is equivalent to obtaining the answers.

(3) For multicomponent problems, the choice of successive trial value is very simple, and no special consideration for very small quantities of a component in distillate or bottoms stream is necessary.

(4) If the real starting composition, holdup and corresponding flow rate and time lags are used, the calculations describe the approach to steady state.

(5) This method can be used to solve multiplecolumn problems where the columns are interrelated.

(6) The method converges relatively rapidly and stably.

\section{Nomenclature}

$A_{i j}=$ Margules parameters

$A_{i}, B_{i}, C_{i}=$ Antoine constants

$D=$ distillate

$F=$ feed rate

$H_{j}^{V}=$ vapor holdup

$H_{j}^{L}=$ liquid holdup

$L=$ liquid flow rate

$N=$ numbers of plates

$R=$ reflux ratio

$S=$ solvent feed rate

$T=$ temperature

$V=$ vapor flow rate

$W=$ bottom product

$q=$ thermal conditions of feeds

$x=$ liquid composition, mole fraction

$y$ = vapor compostion, mole fraction

$z \quad=$ feed composition, mole fraction

〈Greek letters〉

$\gamma \quad=$ activity coefficient

$\Lambda_{i j}=$ Wilson parameters

$\mu=$ relaxation factor

$\Delta=$ increment

$\varepsilon=$ tolerance errors $\langle$ Superscripts〉

$n=$ iteration number

$L=$ refers to liquid

$V=$ refers to vapor

$0=$ initial value

$1=$ refers to recovery section

" = refers to enriching section

$\langle$ Subscripts $\rangle$

$i=$ component number

$j=$ stage number

$t=$ time

$F \quad=$ refers to feed

$f=$ refers to feed plate

$S=$ refers to solvent feed

$s=$ refers to solvent feed plate

\section{Literature Cited}

1) Acrivos, A. and N. R. Amundson: Chem. Eng. Sci., 4, 29 (1955)

2) Atkins, G. T. and C. M. Boyer: Chem. Eng. Progr., 45, 553 (1949)

3) Benedict, M. and L. Rubin: Trans. Am. Inst. Chem. Engrs., 41, 353 (1945)

4) Bonilla, C. F.: Chem. Eng. Progr., 37, 669 (1941)

5) Hala, E.: "Vapor-Liquid Equilibrium Data", Pergamon Press (1968)

6) Hirose, Y. and H. Hiraiwa: Kagaku Kōgaku, 32, 998 (1968)

7) Ishikawa, T. and M. Hirata: Kagaku Kōgaku, submitted

8) Lee, K. T. and K. Kammermeyer: Chem. Eng. Progr. Symp. Ser., 49, 99 (1953)

9) Lewis, W. K. and G. L. Matheson: Ind. Eng. Chem., 24, 496 (1932)

10) Lyster, W. N., S. L. Sullivan, D. S. Billingsley and C. D. Holland: Petrol. Refiner, 38, 221 (1959)

11) Margules, M.,: Akad. Wiss. Wien, Math. Naturw. Kl. II, 104, 1243 (1895)

12) Rose, A., R. F. Sweeny and V. N. Schrodt: Ind. Eng. Chem., 50, 737 (1958)

13) Sadamoto, S., M. Kodama and M. Yorizane: Kagaku Kōgaku, 33, 557 (1969)

14) Shono, H. and M. Hirata: Kagaku Kögaku, 33, 1236 (1969)

15) Sugie, H. and I. Yamada: Kagaku Kõgaku, 32, 273 (1968)

16) Tanaka, S. and I. Yamada: Kagaku Kögaku (Chem. Eng., Japan), 28, 661 (1964)

17) Thiele, E. W. and R. L. Geddes: Ind. Eng. Chem., 25, 290 (1933)

18) Wilson, G. M.: J. Am. Chem. Soc., 86, 127 (1964) 